\title{
Dialogic Pedargagogy
}

\section{Challenging the politics of education: Intertwining dialogic pedagogy with a research-based practicum for first-year pre-service teachers}

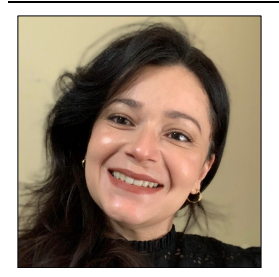

Perla Barbosa

New Mexico State University, USA

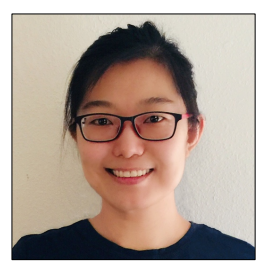

Wenjie Wang

New Mexico State University, USA

\begin{abstract}
The public education system in the United States has long been under assault from neoliberal educational reforms. Those reforms have been characterized by anti-democratic and homogenizing assessment methods and systems that reinforce the banking model of education. In this model, students learn to passively and uncritically consume the knowledge transmitted to them in school. In order to counteract the banking model, this research urged first-year, preservice teachers (PSTs) in an Introduction with Internship in Bilingual/ESL Education college coursework to engage in a dialogic problem-posing pedagogy grounded in a Freirian perspective. PSTs conducted a mini research-based practicum (RBP) that was six weeks long and required a total of 24-hour field observations across local public elementary schools. The RBP framework consisted of a research question, a mini literature review, practicum observations, findings, a group-written report, and a group presentation. In this study, we analyzed the RBP process and data sources that responded to our guiding question: What counts as good teaching according to PSTs? The major findings included: (a) good teaching means relationship building, (b) good teaching starts with understanding the multiple roles of the teacher, and (c) good teaching is inclusive. We discussed the transformative moves that PSTs went through while engaging in a dialogic problem-posing pedagogy. Teacher-educators (TEs) can benefit from this study, as the viability of the transformative effects of a dialogic problem-posing pedagogy, along with its challenges and coping methods, were discussed.
\end{abstract}

Keywords: teacher preparation program, field experience, pre-service teachers, dialogic problem-posing pedagogy, research-based practicum, conscientização.

Perla Barbosa holds a Ph.D. in curriculum and instruction with a focus on language, literacy, and culture from New Mexico State University, and a master's degree in applied linguistics from the University of Massachusetts Boston. In addition to her experience as an EFL teacher in Brazil, Dr. Barbosa has served as a teacher educator and university supervisor for K-12 public schools in New Mexico, USA. Her research, deeply influenced by the work of Paulo Freire, is bonded with her teaching, which engages education students in dialogic problem-posing pedagogy to unpack the political and ideological aspects that underlie curriculum, instruction, and assessment. Her research also encompasses bilingual and ESL education grounded on the participatory action research paradigm.

Wenjie Wang holds a Ph.D. from the Department of Curriculum and Instruction, School of Teacher Preparation, Administration, and Leadership at New Mexico State University. She has served as a teacher educator and liaison with early childhood, and elementary teacher education programs. She has engaged in supervising pre-service and in-service teachers' practicum and student teaching. Her specialization and 
research interests mainly focus on family-school-university-community partnerships, immigrant children and their families in border school communities, early childhood/elementary teacher preparation, field supervising experience, ESL/bilingual/multilingual education, and anti-bias critical multicultural education.

\section{Acknowledgments}

We would like to express our deepest appreciation to the editors and peer reviewers who delivered insightful and detailed feedback. We couldn't reach to this final result without their generous comments and recommendations.

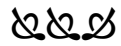

\section{Introduction}

The public education system in the United States has long been under assault from neoliberal educational reforms (Giroux, 2014, 2015; Ravitch, 2010). Those reforms have been characterized by antidemocratic and homogenizing assessment methods and systems that reinforce the banking model (as coined in Pedagogy of the Oppressed by Paulo Freire (2010) of education. In other words, students learn to passively and uncritically consume the knowledge transmitted in school. This is problematic because students complete their schooling without gaining the skills or understanding to participate in a democratic society.

Matusov and Marjanovic-Shane (2017) explained that when public schools adopt a top-down program of studies, they rob students of authorial agency by excluding them from participation in their own learning decisions. In other words, students do not learn how to question, examine, or make decisions on what, why, and how to learn for meaningful participation in a democratic society. Learning becomes less meaningful for students instead of a path for addressing existential life events. To prepare critically cognizant students with social and cultural awareness that prepares them to take part in a democratic society, teachers must have clarity with regard to their own beliefs on education and teaching (Bartolomé, 2004; Freire \& Macedo, 1987). As historical beings, pre-service teachers can gain clarity by working to expand their views during their Teacher Education Program (TEP). Their experiences, knowledge, and practices will determine the future of their students' learning environment, classroom structure, assessment type, and, eventually, the overall educational system.

Bartolomé (2008) pointed out that many TEPs focus solely on technical and didactic strategies of teaching to address cultural and linguistic diversity and fail to address the ideological aspects of it. As a result, many educational goals rooted in diversity, such as reducing achievement gaps, are handled at a superficial level as quick fixes. Yet, most pre-service teachers (PSTs) predictably resist a progressive pedagogy that challenges the status quo and calls for what Freire (2013) states as "the creation of a new attitude" (p.48) that dialogue requires.

In order to start the transformation to democratic curricular and pedagogical practices, we urge first-year, PSTs to engage in a dialogic problem-posing pedagogy by conducting a research-based practicum (RBP) during their coursework leading up to their internship in Bilingual/ESL Education. Dialogic problem-posing pedagogy helps PSTs deconstruct the ingrained epistemological truths that we posit limit the transformation of unjust realities. Possibly, participants should reinvent those realities and resist domestication of their pedagogical understanding in favor of liberation (Freire, 2010; Freire \& Macedo, 1987; Macedo, 2006). 
The RBP model we used was six weeks long, with a total of 24-hour field observations across local public elementary schools. The RBP was presented as a tool for PSTs to identify, examine, and interrogate teachers about curricular and pedagogical practices they observe during their field experience, coursework readings, literature reviews, and their own inquiries about teaching. Introducing a democratic model of transformational pedagogies into a system that values quantitative results over democratic and participatory processes and assessments must happen gradually. Even though the short 15-week timeframe for coursework allowed us to only scratch the surface of the politics of education, the RBP itself prompted students to take ownership of their own learning about how schools work from the perspectives of insiders (e.g., teachers, administrators, staff, parents, students) and raise questions about those perspectives, values, assumptions, practices, and consequences. With this in mind, our guiding research question was: How does a dialogic problem-posing pedagogy transform first-year, PSTs' understanding of what counts as "good" teaching in the context of the current educational system?

In the RBP, teacher-educators (TEs) forged a space in which students scaffolded their dialogues as they questioned the realities of schooling they witnessed in their practicums. PSTs were encouraged to reinvent teaching and learning through discussions about alternatives that position students, especially minority students, as subjects, not objects. In this way, we advocated TEs to use their agentive rights to cocreate knowledge with our PSTs. Through co-authorship of curriculum, TEs transform themselves and also pave the way to transform PSTs' current and future realities in their schools.

This article documents: (a) the implementation of an RBP philosophically grounded in the work of Freire and other critical pedagogues (e.g., Bartolomé, Macedo, Giroux, Shor, and others); (b) the PSTs' beliefs about education, and (c) how research and dialogues were central to the transformation of PSTs' thinking about education and pedagogy. This work also calls attention to the need for TEPs to go beyond the ideological invisibility of assumed best practices (Giruox, 2014) and urges TEs to consistently examine their own levels of conscientização to meet the academic rigor required for the role of a critical pedagogue.

This paper consists of five major sections. Above, we first provided the background, research foundation, purpose, and research question that drove our study. Part two explains our interpretation of dialogic problem-posing pedagogy, grounded in Freire's philosophy of education. Part three describes our study, including an explanation of the research question, participants, setting, method of data collection and analysis, and operationalization of the RBP. The fourth part contains findings and a discussion in which data are presented and evidence is offered with an in-depth, qualitative analysis that responds to the research question. In the last part, we acknowledged the PSTs and our/their challenges during the implementation of the RBP. Finally, we proposed suggestions for TEs (including ourselves) for future implementation of RBPs using a dialogic problem-posing pedagogy.

\section{Theoretical framework: Freirean dialogic problem-posing pedagogy}

We grounded this research and our teaching on Brazilian educator Paulo Freire's philosophy of education, which is a dialogic problem-posing pedagogy. We believe his approach supports this study for several reasons. First, Freirean dialogic problem-posing pedagogy sets the stage for PSTs to take ownership in identifying, examining, and questioning how the political structure of schooling shapes identities and marginalizes or empowers people. Identification, examination, and questioning are daunting tasks for first-year, PSTs and TEs, yet at the beginning of a pre-service program is the best time for this to happen so that PSTs "make their own choices of beliefs based on diverse perspectives they confront in school and society" (Kincheloe, 2008, p. 11). The time is now for future teachers to scratch the surface of the politics of education and the power structure of schooling, and to recognize that education itself is a political act. 
Second, Freire opposed what he metaphorically called the banking model of education in which teachers provide information (metaphorical deposits) to students who receive it and store in their minds (metaphorical accounts) without critical analysis. Students are treated as mere receptacles and are thus diverted from exploring creative processes and diverse epistemologies (Freire, 2010). In other words, the banking model prevents the masses from engaging with their own realities and the world by promoting an ideology of reality as fatalistic. In this research, we as TEs did not treat PSTs as information receptacles (Freire, 2010); rather, we encouraged their own investigations through practicum-based research and critical examination to challenge their mindsets.

Third, Freire $(1998 ; 2010)$ discussed how authentic teaching and learning emerge in dialogue, and that starts where the students are-their problems, perspectives, and dreams-in their dialectical relationship with others in the world. While unpacking their RBP through dialogue, all of us, TEs, and PSTs became familiar with each other's cultural and social experiences, inquiries, and contradictions. These are coded in what Freire called thematic research (Freire, 1998; 2010; 2013). The role of the lead teacher is to decode these experiences, inquiries, and contradictions by presenting them back to students in the form of problems to solve. These problems become what Freire called generative themes. "It is not our role to speak to the people about our view of the world, not to attempt to impose that view on them, but rather to dialogue with the people about their view and ours" (Freire, 2010, p. 96). Freire repeatedly stated that themes represent people's thinking, "which occurs only in and among people together seeking out reality" (p. 108).

Freire referred to the process of transforming oneself and the world for the common good while addressing social power asymmetries as conscientização. He emphasized that reality is not static and is always transforming, as are people. Indeed, this process of "becoming" is "cyclical, recursive, critical and formative" (Souto-Manning, 2010, p. 23). None of us, including PSTs, can be aware of all dimensions of life let alone all at once. As historical beings, our interactions in and with the world and with other humans constantly shape our social and cultural contexts. TEs and PSTs need each other and need to cooperate to analyze and understand their roles in their existential situations. That is, PSTs and TEs become coinvestigators mediated by dialogue. Knowledge emerges through and from this collective inquiry (Freire, 2010, 2013).

The main tenet in Freire's dialogic problem-posing pedagogy is to not impose one's thinking and views on others. Rather, the dialogical aspect of Freire's pedagogy fosters engagement in a critical understanding of the multidimensional realities of the school and classroom. In the RBP, we wanted to implement a methodology by which PSTs became critical observers rather than mere spectators during their 24 hours of field observations. Specifically, we wanted PSTs to utilize their observations as investigative data and progress toward conscientização. The school and the classroom were the sites at which PSTs theorized about emergent cultural and social practices. For instance, instructional methods, which are the most requested lessons from PSTs, cannot be treated as one size fits all. They will not have the same effectiveness and outcomes for every student in any given socio-cultural context (Bartolomé, 1998, 2008).

In implementing Freire's dialogic problem-posing pedagogy, emancipation is a pursuit of the PSTs, as dialogue provides a moment of de-alienation in which they "recognize themselves as producers of culture and reclaim their place in the dialogue" (Puiggrós, as cited in Robinson \& Taylor, 2007, p. 13). Therefore, the dialogical process is praxis, meaning, critical reflection upon reality. The critical reflection calls for actions, but the consequences of those actions must also be the object of critical reflection (Freire, 2010, p. 66; Sanchez-Vazquez, 1977). Finally, in praxis, the dialectical tension that emerges in dialogue 
leads the participants (PSTs and TEs) to modify their social attitude (Fals-Borda, 1985) during the process towards emancipation.

The idea of including a research-based practicum in our coursework also sprang from Freire's juxtaposition of teaching and research. Research stimulates reflection on prospective teachers' assumptions of what counts as good teaching, curriculum, and assessment, along with the problematization of the macro context of schooling. That context includes values and policies that ignore how the social order shapes how we think and what we believe.

Last, by introducing a research-based practicum at the beginning of a TEP program, prospective teachers receive the message that teachers who want to become transformative intellectuals (Giroux, 1997) must admit their unfinished natures (Freire, 2010) as they learn to conceptualize their practice. This helps them avoid the blind adoption of pedagogical methods and activities just because they are put forth as best practices. According to Freire (1998):

$[T]$ here is no such thing as teaching without research and research without teaching. One inhabits the body of the other. As I teach, I continue to search and research. I teach because I search, because I question and because I submit myself to questioning. I research because I notice things, take cognizance of them. And in so doing, I intervene. And intervening, I educate and educate myself. I do research so as to know what I do not yet know and to communicate and proclaim what I discover. (p. 35)

Freire's words provided us the niche we needed to implement a rigorous learning process in which PSTs engaged in a dialogical pedagogy to make sense of their inquiries. These inquiries were the foundation upon which they developed their RBPs that addressed issues that were relevant to them. Through this project, we as TEs intended to regain our academic autonomy despite the limitations that TEPs have established. EP administrators design programs in conjunction with $\mathrm{K}-12$ school curricula and assessments, and TEP accreditation relies on quantitative results of PSTs 'performances (Giroux, 2014). In turn, K-12 curricula and assessments are the results of state legislators' decision-making on educational policies in complicity with business companies (Giroux, 2014, 2015; Nader, 2012; Weiner, 2012). The cycle of accountability is perpetuated at the expense of a linguistically, culturally, and civically responsive education.

In conclusion, we argue that the political aspect of this research challenged PSTs to recognize the discriminatory, anti-democratic, and unequal ideologies throughout the current educational system. The high stakes accountability system was always at the forefront of dialogues, as this educational system is imposed upon teachers as a collection of set-in-stone instructional practices conveyed in policies and topdown curricula and assessments.

\section{The Study: Dialogic Pedagogy through a Research-based Practicum (RBP)}

\section{Guiding Research Question Explained}

How does a dialogical analysis using problem-posing pedagogy transform first-year, PSTs' understanding of what counts as "good" teaching in the context of the current educational system?

Based on our previous experience with PSTs, we recognized that they come to the TEP with their ideas and beliefs about education as well as good intentions. For example, their willingness and enthusiasm to improve English proficiency in English language learners were unanimous. Through examples like this, 
we realized that their good intentions indicated the lack of a deeper understanding of educational issues. The problem they did not realize was that (most of the time) English immersion is encouraged instead of a well-structured bilingual program (Crawford, 2004). Another problem they did not initially recognize was the systemic failure to seek out the root causes of achievement gaps that affect students in the linguistic and cultural minorities; namely, the inequalities of the wider society that are reflected in the classroom. According to Bartolomé (2008):

The combination of a meritocratic view of the social order combined with an assimilationist ideology and a deficit orientation proves to be an especially deadly one because it rationalizes disrespect for minority students 'native languages and primary cultures, misteaching them English and about the dominant culture, and then blaming their academic difficulties on the students themselves . . . [This scenario is an example of] dysconscious racism (King, 1991) and other discriminatory tendencies-tendencies that in the end reproduce the very dominant oppressive ideologies [that] created the need for the latest teaching methodologies. (p. xix)

If PSTs fail to reason about their good intentions and disregard the fact that not all students' home cultures will be reflected in the school culture (Villegas, 1988), instead of encouraging students to achieve academic success, the PSTs will become teachers who continue to fail students with minority home cultures.

Second, we were intrigued when we noticed the following phrases: "control the students"; "empower students"; "safe space for poor students"; "Spanish speakers have more difficulties learning the content," and; "students need strict rules to behave" or "behave properly," referring to how to discipline students behaviorally and intellectually. Similarly, also despite good intentions, those phrases and sentences may reproduce the dialectics of domination and subordination that exist in today's social order. Even assuming that students from minority groups have the same opportunities as socially privileged students, Bartolomé (2004) highlighted that if these dialectics of domination and subordination are unconsciously reproduced and remain unexamined, "1) they blame the minorities themselves for any disadvantages they experience rather than blaming White racism or other oppressive aspects of the system, and 2) they oppose policies designed to increase minority opportunities such as bilingual education and affirmative action" (p. 100). In other words, if good intentions to provide equal opportunities are not examined through the lens of wider societal expectations and dominant ideologies, we do a disservice to minority students and push them to drop out of school. Therefore, teaching methodologies should not be dissociated from ideological and political influences with which education is infused.

PTSs' beliefs about education and teaching emerged throughout the semester and consequently during their RBP became themes or issues examined in this study. For example, the phrases listed above are also commonly heard in field experiences and are normalized with the understanding that those are the best attitudes to have toward students, regardless of the students' social and cultural background. Based on our understanding, we aimed to analyze if PSTs transformed how they framed and re-framed their understanding of good teaching by engaging in a dialogical problem-posing and RBP. It is through dialogue that individuals continuously transform or, in Freire's terms, participate in the process of becoming. We expected that the PTSs' words aligned with their good intentions during their RBP. At the same time, we as teacher educators (TEs) strived to be vigilant, not to contradict ourselves, and not to impose our language on them.

We believe PSTs and TEs need to co-construct new ways of understanding and conceptualizing schooling through dialogue, replacing the original, unexamined beliefs with which they came into their 
coursework with a "new" language that reflects the new construction(s) that emerged during the RBP. Drawing on Halliday's (1999) functional semantics, we observed that "the context for language as text", and "language as a form of action, as the enactment of social relationships and social processes" (p. 6). Our understanding is that if language is action, then what we say and believe is what we will do, regardless of our awareness of the intricacies or nuances of our language or belief. There is no neutrality in any language manifestation. Halliday (1999) discussed that culture becomes the context for language as a system, and "language as a form of reflection, as the construal of experience into a theory of model of reality" (p. 6). It was through these lines of inquiry and philosophy that our research question was formed and investigated.

\section{Setting and Participants}

This study took place at a university located in a southwestern city close to the border between the United States and Mexico. We approached 37 students in two different course sections, and 23 consented to participate in our research. Our participants were first-year undergraduate education students in a threecredit-hour class called Introduction with Internship in Bilingual/ESL Education. In addition to a supervised fieldwork experience, the course description includes the foundational component of the structure, organization, governance, and policies of the American public-school system, and focusing on the state level.

Despite being located in an area with a high concentration of Latinx, our participants self-identified as several diverse ethnic groups, including Caucasian, Hispanic-American, African American, and Native American. They also self-identified as working-class or middle-class and ranged in age from 18 to late 20s. There were two male and 21 female participants. About half of them considered themselves as bilingual in English and Spanish, while the other half was English monolingual.

Participants were required to complete an on-site field observation totaling 24 hours spread over six continuous weeks during the second half of the semester. We met in the classroom on a weekly basis during their field observation period. The TEP administrators placed students/PSTs at local elementary schools, but the students/PSTs were responsible to initiate contact with their schools and their respective cooperating teachers to negotiate their practicum/field experience schedules.

\section{Methods of Collecting and Analyzing Data}

Our primary sources of data for this study were: 1) TEs' field notes and weekly reflections based on dialogue outcomes and our feedback to PSTs, 2) PSTs' fieldwork reflection essays, 3) PSTs'“ Why I Teach" essays, 4) PSTs' RBP essays and oral PowerPoint presentations that included their research questions, a mini literature review, results, and findings, and 5) PSTs' feedback on the RBP projects in terms of structure, activity distribution timeline, and meaningfulness. With this data, we had many opportunities to examine students' levels of critical consciousness on what they consider to be good teaching, how that unfolds from their perspective, and their opinions about the classroom social practices they observed in the field.

We employed qualitative content analysis using an inductive approach to analyze our data and seek evidence of first-year, PSTs' transformation of their understanding of what counts as good teaching in the current educational context. Since data was collected from five sources, data from each source was separately analyzed and compared, but findings were combined and reported as a whole. Thus, we were able to view and review data from specific to general and compare each data source thoroughly. 
We performed an inductive content analysis in four stages: (1) coding and grouping, (2) categorization, 3) mapping, and 4) comparing and interpreting. First, we coded and grouped the data through several rounds of reading and re-reading (Saldaña, 2009). We coded as we read our field note reflections and feedback, and also as we read the PSTs' "Why I Teach" reflection essays, their RBP essays, presentation slides, and feedback. Multiple coding cycles occurred as we continuously highlighted ideas, concepts, and themes.

Second, after we completed the coding, we then categorized it. We first placed the data into broad categories and then further classified them into subcategories, including building a curriculum collaboratively, democratic practices, problem-solving, in-depth analysis of current educational policies and schooling structures, questioning "best practices" and standardization, collective inquiry and decisionmaking, reflection-action-reflection (praxis) in conducting the RBP, and negotiation of tensions and contradictions. This process helped us to further explore the research question, discover issues, and review ideas (Lincoln \& Guba, 1985).

The third step was mapping. By mapping, we generalized categories and subcategories and found clear evidence with which to respond to the research question. Mapping showed us the critical transformation concerning how first-year PSTs understand good teaching, the ideological and political influences hidden in one-size-fits-all teaching strategies, and reflections on more inclusive teaching alternatives that resist inequalities in curriculum, pedagogy, and assessment (Bartolomé, 2004).

The last step was comparing and interpreting data. This process was informed by Freire's theory of education and pedagogy and allowed us to draw solid conclusions. We wrote our analysis and findings based on various themes that crossed multiple data sources. For example, a common theme across the data was understanding the multiple roles of the teacher. This theme was widely and deeply discussed by PSTs, addressed in their essay reflections, "Why I Teach" essays, RBP essays, and oral presentations. By comparing their understanding at the beginning versus the end of the semester, we could distinguish their changes in mindsets and actions; namely, the transformation process.

\section{Overarching Course Process}

Introducing a dialogical problem-posing pedagogy at the beginning of coursework creates resistance, and should be gradually implemented (Barbosa, 2018; Fals-Borda, 1985; Fals-Borda \& Rahman, 1991; Pacheco, 2016). By enforcing participation in a democratic sense, we would be contradicting the very nature of dialogic pedagogy and would thus revert to the authoritarian banking model. As a result of us as TEs gradually releasing our power in dialogue mediation, PSTs and TEs developed a relationship of trust in which collective self-development replaced grading as a punishment. Dialogue as a way of co-constructing meaning, and hence a way of learning, started taking shape (Freire, 2010). By the fourth week, this relationship of trust had developed, and we introduced the RBP in the sixth week, at which time the PSTs started their fieldwork.

The reason for the increase in dialogic engagement lies in the nature of the project, in that the RBP led students to recursively make meaning out of their fieldwork observations as they sought answers to their research questions. Therefore, instead of final results, the coursework was intended to benefit participants through the collective de-construction of their pedagogical beliefs and their day-to-day discovery of emerging subjectivities they found hidden in social practices of schooling. In this sense, dialogue became a way to co-construct new knowledge instead of dialogue as the expression of individualistic opinions to make a point. Last but not least, the dialogic and research processes nurtured students' understanding of their agency. 
In this vein, generative themes emerged as a methodology in our classes. The very process of thematic investigation is educational because teachers and students become co-researchers by tapping their authentic perspectives about the same issue; that is, they investigate beliefs usually left unexamined or taken for granted. "Education and thematic investigation, in the problem-posing concept of education, are simply different moments of the same process" (Freire, 2010, p. 109). In turn, themes emerge in concrete representations in which opposite themes are also revealed, for each theme interacts with its opposite. By concrete representation we mean scenes they observed in their field experience such as teacher-student's relationship, or how students interact with each other during group activities. By themes, we mean concepts or attitudes that emerge from those representations such as relationship-building in negotiating classroom attitudes and learning strategies respectively. The opposite themes would be a topdown relationship for both teacher-students and students-students relationships. In this research, PSTs' emergent practicum observations were translated into our course text or themes (curriculum) for us to problematize and seek answers about PSTs' transformation through the RBP.

\section{A Lesson Moment}

The following is a prototypical "lesson moment": during the RBP and throughout the semester, classroom management was a constant theme. PSTs were concerned about being able to handle large groups of students, specifically in elementary education. They explained that the age range of elementary students requires close attention to be paid to their ethical development. However, some PSTs reported that historically implemented rewards and punishment provided immediate behavior "correction," or correction that was due to the enforcement authority's ability to give detention or suspend a student. One group questioned the balance of authority and freedom, and self-assigned Freire's work after asking one of the TEs for readings on the theme of authority.

This group also pointed out that the opposite of punishment is immediate rewarding. These practices may instill anger, silence, and the perpetuation of the misbehavior elsewhere because these punishments don't help children understand how to live in society. The participants explained the progress that restorative justice or restorative practices make in teaching kids to take responsibility for their actions through the design of an action plan that interrupts the repeated misbehavior.

\section{Ongoing Discussions and Reflections}

The central aspect of the discussion concerning the theme of authority highlighted that what PSTs experienced through observation and what they brought from their experiences in the classroom provided the groups with several perspectives and strategies on how to manage a classroom. We strived for dialogue that did not undermine each other's level of consciousness on critical situations and viewpoints. Another important characteristic of our dialogic methodology was to bring new ideas to the forefront of discussion, such as the importance of conceptualizing discipline as everyone's responsibility, including students, to make the classroom climate inclusive and democratic.

Students understood that they have freedom of expression as they explained how their CTs solved behavioral problems and as they reflected on those solutions. PSTs went back and forth with this theme of authority as they investigated and dialogued about the school regulations about discipline, the similarities between the language used by the school administrators, and the language used by the military (e.g., detention), and PSTs' own developing management strategies. PSTs understood that this theme (authority) needed to be explored because they wanted to find the means through which to be part of the change to a more humane type of education without being patronizing, and how to bring awareness to teachers of their individual responsibilities and what can be achieved through dialogue. 


\section{Research-Based Practicum (RBP)}

The RBP fieldwork involved three main parties: (1) our students/PSTs, (2) the public-school teachers who served as cooperating teachers (CTs), and (3) us, teacher educators (TEs). Concerning the administrative formalities of fieldwork, our role as TEs was to mentor PSTs on how to get necessary background clearance, how to contact the school to schedule a pre-visit, how to keep up with the fieldwork protocol (observation notes, log, and reflection) requirements, as well as orient them about professionalism and communication etiquette.

The RBP created the spaces in which PSTs could practice the skills of democracy (Giroux, 1997). The project provided PSTs with an agentive backbone for critical inquiry on the realities in different school sites and the risk-taking required when sharing perspectives and beliefs. Decision-making was also a strong characteristic of the RBP process because PSTs started seeking ways to transform the realities they once problematized. Therefore, participants were not merely providers of information or followers of an outside protocol, but instead became co-researchers and decision-makers in every step in the process of collective inquiry.

\section{RBP Operationalization}

Phase 1: In this phase, the PSTs investigated their past and present schooling experiences through individual and collective brainstorming. Also, in this phase students interviewed an experienced professional, such as a teacher who has taught for 20 years, or a representative of an older generation (such as a grandmother) who attended school 40 or 50 years ago. In class, we discussed possible questions and follow-up questions depending on their interviewee's responses. A week later, students presented their findings.

Phase 2: Research questions were developed in this phase. The PSTs gathered in groups of two, three, or four to brainstorm their inquiries. They built their research questions on issues raised in Phase 1. In their groups, each member proposed a question, and then negotiated one main theme that was of common interest to all members. Thus, by drawing on individual inquiries, they came up with a group research question. They still made use of their individual research questions in individual field observation reports. As TEs, we assisted each group in the development of their research question to ensure their questions had the potential to generate robust findings (Foss \& Waters, 2007). We, the TEs, and the PSTs had to revisit each research question, as our reflections and discussions brought new issues to the forefront.

Phase 3: This phase was a literature investigation. We (TEs) provided an orientation on how to use the library database to find peer-reviewed research articles that provide insights for their research questions. The PSTs researched individually, and then came together in their groups to share their findings and perceptions.

Phase 4: Phase 4 was the practicum fieldwork. In preparation for field observation, we read field observation protocol and discussed various ways to write and compile ethnographic field notes. Some PSTs took the initiative to interview their respective CTs to gather further information about the student population and student histories at their field placement.

Phase 5: Phase 5 was the findings phase in which the PSTs gathered to discuss their findings with their initial research questions. They negotiated how they would structure their findings in a paper and how they would share in class in a way to generate thematic discussions. 
Phase 6: In Phase 6, the final phase, the PSTs shared their results with their fellow PSTs. They started by situating their audience with the school context (location, demographics, and type of bilingual/ESL program) at their fieldwork location. They shared their research questions and presented their findings, emphasizing the similarities and differences they encountered in different grades and schools, or different grades within the same school. Finally, we opened up the discussion to pose alternative views for the events they found critical in terms of teaching methodology, classroom management, and school district programs such as restorative justice, gun control, and bullying prevention.

\section{The Roles of Cooperating Teachers, Pre-service Teachers, and Teacher-Educators}

The CTs' roles primarily involved hosting the PSTs. CTs generously presented PSTs with instruction on what a curriculum looks like, along with how they bridged the intersection of school policies and classroom practices. CTs were role models for lesson planning and implementation, and for ways to accommodate special needs children and manage a classroom. They fielded a lot of questions from the PSTs!

The PSTs' roles were to observe the dynamics of the classroom from the perspective of the teacher and visualize themselves in the situations they observed. That was how they began to consider the settings in which they will work in the future and what dispositions they will need to navigate those settings.

As TEs and teacher-researchers, we were aware of the influence of our subjectivities in mediating dialogue with PSTs and during the process of responding to our guiding research question. According to Madison (2020), "Positionality is vital because it forces us to acknowledge our power, privilege, and biases just as we are denouncing the power structures that surround our interlocutors" (p. 6). First, we were aware of the power dynamics in the classroom. We were the lead teachers and the ones who oriented PSTs for their field experience, which may have influenced how we mediated the dialogues. Second, even though we strived to align our methodology with our practice, there might have been times that we resisted unexamined opinions of PSTs. Yet, as researchers, we had the ethical commitment to acknowledge those moments and renegotiate meanings with the PSTs.

Our influence may have increased when we made our methodology explicit. We openly expressed that the teaching methodology they observed was not merely the transmission of neutral knowledge or conveyance of innocent social practices. Social practices mirror an individual's and a cultural group's values, beliefs, and the intersections of different identities that are shaped and reshaped by and with one's presence in a given environment.

\section{Findings and Analysis}

As stated earlier, although we analyzed each data source separately, we compared and reported them as a whole as we pursued our research question: How does a dialogic problem-posing pedagogy transform first-year, pre-service teachers' understanding of what counts as "good" teaching in the context of the current educational system? To present evidence and answer the research question, we here provide our findings and analysis. The first section focuses on what pre-service teachers (PSTs) understand "good" teaching to be, and the second section focuses on the transformation of PSTs' critical consciousness during their research-based practicums (RBPs). 


\section{Responding to what counts as "good" teaching}

\section{Theme 1: Good teaching means relationship building}

This first theme fell under the Classroom Management coursework module. Based on observations during their field experience, PSTs demonstrated concern regarding misbehaving children and how the types of relationships teachers build in the classroom relate to children's behavior. For example, one PST shared her difficulty coping with children who presented a pattern of misbehavior during instruction time or individual and group activities. Her explanation of the reasons some children misbehave was that, "The children in my classroom get frustrated with their peers because they are slower at grasping a few concepts than the others, so they become impatient, and therefore disruptive" (Maria, field experience report). Another PST shared her ideas about children misbehavior, noting, "I see that the majority of the kids misbehave or disrupt the classroom due to their age, lack of independence, as well as lack of attention they receive from home" (Fernanda, field experience report).

Once PSTs started their field experience, we, the teacher-educators (TEs), used issues that they raised in their field reports as topics for class discussions. In the discussion about misbehavior in class, PSTs first shared their observations with regard to what they thought generated the children's misbehavior. We then discussed how cooperating teachers (CTs) coped with misbehavior in their respective classrooms. In this conversation, PSTs emphasized the importance of nurturing children, principles of mutual respect, and basic courtesy while preserving the children's autonomy and agency. PST Magdalena explained how her CT emphasized relationship building in classroom management and pointed out the structural intersections between school and society.

[In today's observation] I was focusing more on the relationships that the teacher and students shared. Observing the conversations, they shared got me very excited for my future classrooms and sharing that relationship with my students. My cooperating teacher is known to be the teacher that gets all the "troubled kids" in her class, simply because she has proven to work very well with them and encourage them to behave and learn. This inspired me because although I was unable to observe these students from the very beginning, today I was able to witness students and teachers discuss their accomplishments and things to work on. I then asked my cooperating teacher for advice [on how to relate and gain students trust] and she advised me to keep going and never lose motivation even through the hard times. I remember the very first day my cooperating teacher said, 'It 's never the kids. It's the system that makes teaching become hard." I took these as words of wisdom because when times get hard, I have to remember that it isn't hard because of the kids. It isn't the kids 'fault, and I have to try my very best to stay strong for them. (Magdalena, field experience report)

The passage above demonstrates a critical moment of insight. The lesson PST Magdalena learned from her CT, who clearly demonstrated political awareness with her "words of wisdom," was the entry point for our discussion on deficit ideologies. Valencia (2010) pointed out that deficit models are pseudoscientific explanations propounding that minority children's academic problems are genetic and their sociocultural pathologies are associated with their racial and disadvantaged economic status. Valencia (2010) stated that, as an ideological model, the deficit model explains the academic failure of minorities by blaming the victims, which has the practical effect of creating unequal schooling arrangements that prevent minority students from succeeding academically.

With regard to relationship building, another PST pointed out how bringing children's funds of knowledge into the classroom plays a significant role because recognizing their cultural background shows that it is valued and valuable. 
My class was almost full of strictly Spanish-speaking students. That is important to include because culture plays a role in the relationship between students and teachers. Mexican cultures use words like "mijo" and "mija" and the same names many are called at home by their parents. Automatically, the title is comforting, which is why I infer the students are so vulnerable with their teacher that I observed. The students called their teacher "Ms.", but it was very obvious that they saw her as more than that. To them, she was a friend, a mom, and a teacher. (Elena, field experience report)

The next example shows a captured moment that revealed how the act of listening is an essential requirement to build relationships of mutual respect between teachers and children.

My teacher also gathered in a circle with the first graders once a week and they each said one thing they liked or disliked about the week. As a teacher, that is going above and beyond. The teacher was essentially telling her students how much she cared about them without even having to say a word, she just listened and that was enough. (Ana, field experience report)

What the PST described about what the CT was doing was what bell hooks (2010) called "radical openness" (p.10). By listening to children, teachers start to open their minds and understand children, just as hooks (2010) explained that "teachers must be open at all times, and we must be willing to acknowledge what we do not know. A radical commitment to openness maintains the integrity of the critical thinking process and its central role in education" (p. 10). In other words, the PST illustrated with that example that good teaching means creating a supportive environment by listening to children actively.

Theme 2: Good teaching starts with understanding the multiple roles of the teacher

The data for this finding comes from the "Why I Teach" essays in which the PSTs explained their understanding of the role of a teacher. We gave this assignment both at the beginning and the end of the semester and analyzed the responses by comparing each PST first and second essay. The comparison reflected the PSTs' shifts in understanding of the different facets of the teaching profession and the multiple roles teachers have. These shifts happened gradually throughout the PSTs' research-based practicum (RBP).

For example, one PST initially demonstrated awareness of the devaluation of the teaching profession in terms of the salary. By the end of the semester, this PST changed the tone of her response, and instead focused on the importance of relationships in a child's education.

\begin{tabular}{|l|l|l|}
\hline PST 1 & Beginning of semester “Why I Teach" essay & End of semester "Why I Teach" essay \\
\cline { 2 - 4 } & $\begin{array}{l}\text { If I am being completely honest, I never } \\
\text { described what means to be a teacher. I saw } \\
\text { how it could potentially be fun. But when I } \\
\text { thought about the small amount of money I } \\
\text { would be making, I didn't think of being a } \\
\text { teacher once. I thought about other careers, } \\
\text { careers that made money. I am taking this } \\
\text { class because I have to, and I am still trying } \\
\text { to figure out what I want to do. }\end{array}$ & $\begin{array}{l}\text { What has made me want to pursue the } \\
\text { career of teaching is how much the teacher } \\
\text { can influence each student. I think I have } \\
\text { learned a lot about the things in this life } \\
\text { that matter, and at the top of my list is } \\
\text { loving people. I now understand that there } \\
\text { are different instances of being a good } \\
\text { teacher, the first was a parent, the second } \\
\text { was a cheerleader, the third is a friend, and } \\
\text { lastly, a counselor. }\end{array}$ \\
\hline
\end{tabular}


In the first essay, the PST demonstrated a preoccupation with making money and how a teacher's income does not support a decent lifestyle. In the second essay, after experiencing the classroom from the perspective of the CT, the PST's focus shifted from money (or lack of it in the teaching profession) being a priority to the responsibility teachers have in shaping identities. One of the TEs delivered the following feedback to this PST regarding her essays:

Both reflections mirror realities in the teaching profession. My suggestion is that you continue exploring those realities by getting acquainted with the teaching profession at different levels. Feasible actions consist of gathering allies from different settings, such as caregivers, students, and representatives because change starts from the bottom up (e.g., civil rights, the anti-slavery movement, women 's rights and emancipation, farmers 'and workers 'movements). What are your thoughts on that? What could happen if we teachers raise our expectations towards our profession and education? (Teacher-educator, written feedback for the "Why I Teach" essays)

TE feedback was used in class discussions as part of the dialogic problem-posing pedagogy. Although the end of the semester cut short some of our discussions, students took our feedback seriously. Their commitment to our back-and-forth written conversations throughout the assignments was expressed in the PSTs' responses to our end-of-semester survey on the efficacy of our teaching methodology and assignments (results of which are shared later in this article).

PST 2 initially expressed a romantic idea of the role of the teacher, starting the semester with the belief that all that happens in a classroom is a consequence of the teacher's work. As the semester went by, she demonstrated a shift in her belief from individual responsibility to collective responsibility when it comes to teaching, and by the end of the semester, she was taking into consideration the sociocultural context that shapes the education system. She found that teachers also seek allyship with other stakeholders such as, family and community members, administrators, and policy makers.

\begin{tabular}{|l|l|l|}
\hline PST 2 & $\begin{array}{l}\text { Beginning of semester “Why I Teach } \\
\text { essay" }\end{array}$ & End of semester “Why I Teach" essay \\
\cline { 2 - 3 } & $\begin{array}{l}\text { As a teacher, I must understand each } \\
\text { student, knowing their background well } \\
\text { and individual needs, and trying my best to } \\
\text { provide what I can to them. }\end{array}$ & $\begin{array}{l}\text { One teacher alone cannot even hope to shape } \\
\text { the future through our kids, but together we can } \\
\text { do anything. You can be a great teacher alone, } \\
\text { but you can't singlehandedly educate the whole } \\
\text { student population. To successfully prepare out } \\
\text { future generations it falls on us to do our best to } \\
\text { work collectively and educate them. }\end{array}$ \\
\hline
\end{tabular}

Theme 3: Good teaching is inclusive

One event that stood out during this research was described in a PST's field report, which we then discussed with the whole class. She gave an example of a situation in which the teacher deconstructed a stereotype of special needs children.

I was fortunate to be in the classroom when that happened and witnessed how the teacher dealt with the situation with so much wisdom. We heard a student with special needs screaming and it sounded very scary. It came from the next door, and all the students got shocked and started whispering, trying to understand what was going on. I don 't remember why the SPED student was there at that time because I had never seen him 
before. I believe someone left the door open and we heard that from inside our room. The teacher heard the screaming and noise. So, rather than ignoring her kids 'curiosity, she completely changed what she had planned to do that lesson and improvised a lesson on diversity and inclusion. It was amazing! The teacher used this moment and started a conversation on what it means to be different or what makes us different, how we deal with our differences, how comparing each other doesn't give us the whole picture of who we are ... she asked questions and gave and asked for examples. (Sonia, field experience report)

PST Sonia sharply captured that moment in which her CT improvised content based on a real-life incident that triggered her children's curiosity and fear describing how the CT used her philosophy about ethics in the classroom in a real-life situation. The CT did not hesitate to depart from the official curriculum despite the deadlines attached to it.

PST Sonia's experience piqued the interest of the entire class regarding how to better include children with special needs in daily interactions, and even encouraged one of the quietest PSTs to start talking in class. The quiet PST was pursuing a Special Education (SPED) degree, inspired by her mother's job working with visually impaired students. This fostering of idea exchange-PST Sonia sharing her experience being the catalyst for the quiet PST to engage-demonstrated that a dialogic problem-posing pedagogy grounded in power symmetry builds relationships of trust and respect among PSTs.

\section{Responding to transformation pursuant to the RBP}

Theme 1: Critical consciousness is an ongoing process of reflection-action-reflection (praxis)

As explained earlier in this article, dialogic problem-posing pedagogy was nurtured throughout the RBP process. Specifically, PSTs first created individual research questions. Then, through dialogue, they shared their questions and collectively (in their group) negotiated one research question to explore based on their common curiosities. In other words, this process was their first step in finding common ground as a community. Next, the PSTs refined their group research question through mini literature reviews, individual reflections, fieldwork observations, and their findings, which they presented as a group in class. Going through this process, the PSTs concluded that there were no single answers to their research questions, let alone one single truth that fits every social context. Rather, answers vary depending on different school demographics, grade levels, and specific classroom situations. The cycle of reflectionaction-reflection happened spontaneously because of the democratic nature of the RBP framework.

Table 1 illustrates how the two different groups of PSTs engaged in praxis and how we mediated the RBP process. Note that their experiences are streamlined and paraphrased, using the voices of two PSTs in each group. The RBP process is complex, cyclical, multidimensional, and fluid, just like human thinking. We stated their main ideas rather than display entire dialogues for brevity and ease of understanding.

Table 1. Praxis: Pre-service teachers' RBP process

\begin{tabular}{|l|l|l|}
\hline Scaffolding praxis & Group One & Group Two \\
\hline $\begin{array}{l}\text { Step 1. Reflect on } \\
\text { past schooling } \\
\text { experiences and }\end{array}$ & $\begin{array}{l}\text { Student 1: Building a student- } \\
\text { teacher relationship is important. }\end{array}$ & $\begin{array}{l}\text { Student 1: It is challenging to have students } \\
\text { with special needs in the same classroom } \\
\text { with the regular student population. }\end{array}$ \\
\hline
\end{tabular}




\begin{tabular}{|c|c|c|}
\hline $\begin{array}{l}\text { generate initial ideas } \\
\text { for research. }\end{array}$ & $\begin{array}{l}\text { Student 2: Teachers must build } \\
\text { foundations and keep interacting } \\
\text { with students. }\end{array}$ & $\begin{array}{l}\text { Student 2: Special needs students and the } \\
\text { regular student population must interact. It } \\
\text { can promote inclusion. I also think that it is a } \\
\text { challenge for the SPED teacher and even for } \\
\text { the special needs kids to follow what is } \\
\text { going on in the classroom. }\end{array}$ \\
\hline $\begin{array}{l}\text { Step } 2 \text {. Draft the } \\
\text { research question. }\end{array}$ & $\begin{array}{l}\text { Does the personal relationship } \\
\text { between a student and the } \\
\text { teacher affect the way a student } \\
\text { learns? }\end{array}$ & $\begin{array}{l}\text { What does the interaction between special } \\
\text { needs students and the general student } \\
\text { population look like during recess? }\end{array}$ \\
\hline Step 3. TE comments & $\begin{array}{l}\text { What do you mean by personal } \\
\text { relationships? When you say } \\
\text { relationships affect the way a } \\
\text { student learns, explain what do } \\
\text { you mean by "the way"? Are you } \\
\text { also thinking of how a kid's } \\
\text { culture informs him about how } \\
\text { to interact with people? How is } \\
\text { kids' culture similar or different } \\
\text { from the teacher's culture which } \\
\text { informs their interactions, and } \\
\text { whether the similarities or } \\
\text { differences determine student- } \\
\text { teacher relationship outcomes? }\end{array}$ & $\begin{array}{l}\text { That research question will give us good } \\
\text { insight into how important it is to } \\
\text { experience many types of diversity within } \\
\text { the classroom. } \\
\text { As you want to observe interactions during } \\
\text { recess, how much time will you actually } \\
\text { have to observe? } \\
\text { If you have enough time to observe recess, } \\
\text { what will be the next step after you explore } \\
\text { the interaction between students with } \\
\text { special needs and the general student } \\
\text { population? }\end{array}$ \\
\hline $\begin{array}{l}\text { Step 4. PST's } \\
\text { reflections from field } \\
\text { experiences and TE } \\
\text { feedback }\end{array}$ & $\begin{array}{l}\text { The focus is not whether or not } \\
\text { there is a personal relationship } \\
\text { between the teacher and the } \\
\text { students, but how it is built and } \\
\text { how that relationship affects } \\
\text { students. Possible effects may } \\
\text { emerge in discipline-specific } \\
\text { knowledge, psychological, } \\
\text { emotional and interpersonal } \\
\text { skills, and how the apprentice of } \\
\text { relationship outcomes influence } \\
\text { children to either apprentice } \\
\text { values, beliefs, and behavior or } \\
\text { develop awareness of the norms } \\
\text { of each place [social context]. }\end{array}$ & $\begin{array}{l}\text { Due to the lack of time available to observe } \\
\text { recess, the research question had to be } \\
\text { revised. The ultimate goal was to know how } \\
\text { diversity in the student population benefits } \\
\text { learning. }\end{array}$ \\
\hline Step 5. Major actions & $\begin{array}{l}\text { Mediated by the teacher- } \\
\text { educator, the group revised the } \\
\text { research question. One } \\
\text { mediation intervention consisted } \\
\text { of avoiding yes/no questions. }\end{array}$ & $\begin{array}{l}\text { Revised the research question based on } \\
\text { dialogue with the whole class on the theme } \\
\text { of inclusion and diversity. Students shifted } \\
\text { the focus away from highlighting the } \\
\text { limitations of special needs kids and started }\end{array}$ \\
\hline
\end{tabular}




\begin{tabular}{|c|c|c|}
\hline & $\begin{array}{l}\text { Instead, the group understood } \\
\text { that to foster robust findings } \\
\text { with complex results and } \\
\text { insights, researchers should use } \\
\text { "what" and "how" questions. }\end{array}$ & $\begin{array}{l}\text { questioning the potential of all learning } \\
\text { together in the same space. }\end{array}$ \\
\hline $\begin{array}{l}\text { Step 6. Final research } \\
\text { question }\end{array}$ & $\begin{array}{l}\text { How does the personal } \\
\text { relationship between the } \\
\text { students and the teacher } \\
\text { influence the students' learning? }\end{array}$ & $\begin{array}{l}\text { How does interaction between students } \\
\text { with special needs and the general student } \\
\text { population influence classroom dynamics? }\end{array}$ \\
\hline $\begin{array}{l}\text { Step 7. Reflections } \\
\text { from findings }\end{array}$ & $\begin{array}{l}\text { 1. Personal relationships can be } \\
\text { reflected in multiple ways, such } \\
\text { as name-calling, gestures, and } \\
\text { body language. For example, } \\
\text { instead of the teacher giving a } \\
\text { misbehaving student an angry } \\
\text { look, we witnessed a serious } \\
\text { look, followed up by exploring } \\
\text { what led the student to } \\
\text { misbehave. } \\
\text { 2. Personal relationships are } \\
\text { connected to culture. For } \\
\text { example, most of the CTs used } \\
\text { Spanish words when relating to a } \\
\text { student who was having trouble } \\
\text { working through a negative } \\
\text { interpersonal situation. } \\
\text { 3. Positive personal relationships } \\
\text { create a positive learning } \\
\text { environment. When teachers } \\
\text { shush and yell at students, } \\
\text { students don't see the teacher's } \\
\text { authority, but rather see the } \\
\text { teacher as an authoritarian who } \\
\text { is removing their agency. Most of } \\
\text { our CTs showed love and care } \\
\text { while showing children the } \\
\text { consequences of their actions } \\
\text { and how those actions delay } \\
\text { their learning and success. }\end{array}$ & $\begin{array}{l}\text { 1. Students with special needs bring a reality } \\
\text { that all children will find outside the } \\
\text { classroom. Students have opportunities to } \\
\text { interact with each other, with the general } \\
\text { population respecting the type of } \\
\text { impairments special needs students have } \\
\text { and developing empathy. } \\
\text { 2. In other classroom settings, students with } \\
\text { special needs were often pulled out, which } \\
\text { was enough to disturb other students 'focus. } \\
\text { We also noticed that children look at the } \\
\text { special needs children as not belonging in } \\
\text { the "normal" environment. Doesn't this } \\
\text { create intolerance, isolation, and separation } \\
\text { between people? } \\
\text { 3. We also noticed that if a classroom has } \\
\text { too many students with different types of } \\
\text { special needs and only one SPED teacher, it } \\
\text { is difficult for the teacher to assist with each } \\
\text { individual's needs. Perhaps the way classes } \\
\text { are set up makes for inefficient inclusion. }\end{array}$ \\
\hline
\end{tabular}




\begin{tabular}{|l|l|l|}
\hline $\begin{array}{l}\text { Step 8. PSTs plans for } \\
\text { future action }\end{array}$ & $\begin{array}{l}\text { Understanding students' } \\
\text { cultures, family values, social } \\
\text { status, and their domestic } \\
\text { background builds a relationship } \\
\text { of mutual respect. The } \\
\text { relationship between teachers } \\
\text { and students cannot be one of } \\
\text { punishment every time children } \\
\text { break the rules, but it should be } \\
\text { one of communication and } \\
\text { understanding of consequences } \\
\text { (good and bad) of actions. }\end{array}$ & $\begin{array}{l}\text { There is a need to read more research on } \\
\text { this topic and have conversations with } \\
\text { special education teachers. Those actions } \\
\text { would help us understand students with } \\
\text { special needs and how to create more } \\
\text { inclusive classroom? accommodations. The } \\
\text { general student population is also a part of } \\
\text { this process. One idea was to create more } \\
\text { collaborative and cooperative activities } \\
\text { within the classrooms so that children } \\
\text { develop more empathy for each other. }\end{array}$ \\
\hline
\end{tabular}

As shown in Table 1, both groups demonstrated a predisposition for conscientização. Despite starting the process within inaccurate understandings, their understanding of realities advanced in praxis. For instance, in the initial discussion, the second group demonstrated a concern about having SPED and non-SPED children in the same classroom. They explained that they didn't see SPED children make progress because the pace of the other children and the lead teachers was too fast for them. Even though that was a timely insight, they were fatalistic with regard to the issue, and did not question the potential for transformation. There were other examples of naïve ways of thinking that PSTs approached the issue in the first group's initial remarks. Yet, by the end of the RBP, both groups had significant insights on their respective topics. The first group articulated how authority is differentiated from authoritarian. The second group articulated that the educational system, despite its history of working with special needs children, still needs to change to incorporate methods and philosophy by which all children collaborate on their collective development in solidarity.

Theme 2: PSTs take ownership of their learning

Example 1: PSTs adjust the placement protocol to the real-world administrative context of schools

At the beginning of the RBP, TEs provided field placement information to PSTs. PSTs' first responsibility was to contact their CTs via email to schedule a pre-visit. They had to act quickly because there were only six weeks before the end of the semester to complete their RBP. Some PSTs complained they did not receive an email or call back from their CTs by the end of the week that they attempted contact. They were concerned about failing to fulfill the RBP hours according to the TEP protocol.

This issue was brought up in class, and the TEs suggested PSTs take into consideration the coordinating teachers' obstacles to replying, such as hectic daily schedules and significant workload. One of the most important dispositions for teachers is the ability to act in solidarity. By developing solidarity with the CTs, PSTs would avoid frustration and not take the lack of response personally. Moved by solidarity, PSTs found alternatives. Rather than passively wait for TEs' feedback and solutions, one PST decided to do a pre-visit to the school on her own, introducing herself (with proper identification) and requesting to meet with her CT. Having a formal face-to-face conversation was a positive start, as the PST showed how committed she was to the school and the CT. This PST was a model for others having the same issue, showing them that they could find a way to solve this problem.

As part of dialogic problem-posing pedagogy, PSTs should have the agency to cope with limiting situations in order to develop problem-solving skills. Doing the opposite of that is a form of oppression, 
which is the foundation of Freire's (2010) conceptualization of banking model. After dismantling problems and co-constructing possible ways to solve them, PSTs better understood their duties and rights, as well as their autonomy, in creating a bridge to the school and the CT. The PSTs became an essential part of negotiating the partnership between the university and the public schools. In becoming committed to their RBP, PSTs also held TEs accountable in our role as proponents of a dialogic problem-posing pedagogy.

Example 2: PSTs problematized the placement protocol by negotiating sites

During their field observation, some PSTs found that being in the same classroom for the 24-hour practicum did not help them to explore their research question. For example, one PST wanted to learn more about bilingual education strategies; however, the majority of the children in the kindergarten class she observed were Spanish speakers. In that particular school, despite offering a two-way bilingual program, the CT struggled to teach academic content in English. Although the PST believed that maintaining the home language was fair and necessary to preserve the children's ethnic roots, she wanted to have a field experience in which she could observe how to teach content in a dual-language educational space.

PSTs were willing to see more learning environments. Although staying in the same classroom was a requirement of the RBP protocol, PSTs still brought up this issue in our dialogues and asked for suggestions, rather than passively following the protocol when it didn't serve them. Finding classrooms at other schools for PSTs before the semester ended was administratively and logistically prohibitive. Thus, we discussed with the PSTs the feasibility of observing two classrooms across different grade levels at the same school site. We had agreed that observations could not be done in more than two classrooms, because the time available was too short. We considered who the PSTs needed to work with to make the placement adjustment they requested, and the PSTs proposed the adjustments to the CTs and the school principal. As a result, PSTs who wanted to observe more than one classroom were accommodated. PSTs embraced the responsibility of having more labor added to their field experience, as scheduling with principals required patience. In doing this, PSTs learned how to find allies who could help them fulfill their needs and took on the responsibility of transforming their RBP into a meaningful and authentic experience.

During our discussion on this issue, our dialogue focused on language learners, culturally responsive teaching, Teaching of English to Speakers of Other Languages (TESOL) strategies, and different types of language and content assessment. The PST who observed a bilingual classroom shared some of her in-depth thoughts, such as: (a) teachers are not the world's rescuers. Some situations are not only hard, they also need attention and effort from the children's families, school administrators, and the community; (b) there is no one-size-fits-all strategy, especially in bilingual education; and (c) teachers are life-long learners and should always seek new challenges.

Example 3: PSTs problematized the placement protocol by negotiating practicum hours

Toward the end of the RBP, some PSTs brought up the issue of their schedules conflicting with Partnership for Assessment of Readiness for College and Careers (PARCC) testing. Specifically, public elementary schools in our district didn't allow PST visits during PARCC testing, so PSTs had to postpone their observations, placing them at risk of not completing their RBP required hours before the end of the semester.

The problem was real, and some PSTs became frustrated with PARCC testing itself, which places pressure on the students, teachers, and public-school administrators. As this situation emerged, we included topics in our discussion such as the connections between the Common Core State Standards Initiative, high-stakes testing, accountability, and holistic assessment. We discussed alternatives in the 
event that a lack of time prevented completion of RBP hours. Some PSTs suggested the reduction of RBP hours, but that was not possible because the total hours were a requirement set by the College of Education administration. Therefore, they proposed the following: (a) interviewing their respective CTs (if the CT's schedule allowed) about questions they had, (b) participating in the after-school program and comparing formal and informal learning practices, 3) attending a parent-teacher conference to focus on family engagement, and (d) auditing teachers' weekly meetings. As a result, PSTs were able to negotiate among the CTs, the schools, the TEs, and themselves regarding ways to make up their hours meaningfully and without sacrificing the goals of the RBP.

\section{Discussion}

Based on the findings, we now extend our analysis from specific results to a discussion of general implications, interpreting the importance of applying dialogic problem-posing pedagogy in helping PSTs reinvent curriculum and instruction through the deconstruction-construction-reconstruction process by questioning both the greater educational system and real-time classroom practices. Specifically, we address three aspects of the implementation of dialogic problem-posing pedagogy through an RBP: collaborative curriculum building, analysis of the greater educational system, and PSTs recognition of their agency.

\section{Dialogic problem-posing pedagogy provided the class with both the text and context to build a curriculum collaboratively, promoting a more democratic teaching practice.}

Dialogic pedagogy from a Freirian perspective is participatory and democratic in nature-it requires power symmetry, which can be achieved through cooperation between PSTs, CTs, and TEs as a course unfolds. Because we strived to present a bottom-up pedagogy, the PSTs' voices were heard throughout the process as we checked in with them about what they observed in their field experience, their inquiries, and discussions of how the issues posed play out in different contexts (i.e., the school, a classroom, a grade level). We as TEs emphasized the topics in which the PSTs appeared most interested, such as classroom management through relationship building. We started our classes by placing their observation(s) into a problem format for general discussion. Dialogue, sharing field experiences, asking for clarification, and expressing disagreement and agreement until finding common ground became the process through which we built our lessons together. This democratic aspect of our pedagogy assured the validity of the research process because the research benefited those involved and emanated from social justice principles. Throughout the course we encouraged deliberation about curriculum as new issues came up that PSTs wanted to address.

The PSTs and TEs together modified the curriculum as class discussion themes were brought forth based on RBP experiences. In other words, the PSTs brought themes and questions to the classroom from the field, and together we incorporated their reflections, experiences, and inquiries into our dialogic classrooms. This is how dialogic problem-posing pedagogy works-it provides ongoing opportunities for PSTs and TEs to reexamine our texts by reading the words as well as examining our realities through reading the world (Freire \& Macedo, 1987).

\section{Dialogic problem-posing pedagogy creates opportunities for problem solving and in-depth analysis of various aspects of current educational policies and schooling structure.}

Since dialogic problem-posing pedagogy is an ongoing problem-solving process rather than a fixed destination, considering and studying various aspects of the same issue while making sure to include forgotten and/or opposing voices is significant to the development of critical consciousness. For instance, by addressing so-called "best practices" that originated under the umbrella of the standardization in 
education, PSTs' understanding of what it means to be a teacher expanded from day-to-day classroom strategies to the relationship of schooling to the greater social structure.

Specifically, the narrative of "best practices" as the essence of teaching was reflected in some of the PSTs' discourses, which was not surprising considering their own schooling was in banking model classrooms. They understood "best practices" as a general method or strategy implemented to fix so-called academic gaps using a predetermined curriculum. Other PSTs presented signs of critical consciousness early on, revealing an openness to discussing ideological aspects of the current educational system that hinder minorities' academic success. The fluidity of our RBP, from the articulation of the PSTs' own research interests to bringing their questions from the field to the class, proved to be effective. Gradually, PSTs switched from talking about "best practices" to questioning the status quo and taking the initiative to do their research. They discussed deep aspects of education that have less chances to be discussed once PSTs become teachers and immerse themselves in the long hours of teaching and the parallel tasks that involve the profession. The PSTs raised the possibility of not being able to implement an inclusive pedagogy to the extent that they wanted because of time needed for daily bureaucratic teaching tasks and a rigid school structure that limits teachers' abilities to educate students beyond the academic curriculum. PSTs started problematizing their inquiries and expanding their consciousness about what is seen as having value in the educational system beyond the banking model.

Moreover, by studying the PSTs' reflections, it became visible in their language that our dialogic problem-posing pedagogy was transforming and expanding their ways of thinking. First, in their later essays, the PSTs offered more detailed and specific ideas about how to be a teacher compared with the superficial statements they made in earlier essays. Second, PSTs' perceptions of the role of the teacher and teaching matured, evidenced by their acknowledgment of the non-neutrality of teachers' and administrators' actions on decision-making and on preparing children to participate in society. Compared to the beginning of the semester when the PSTs had only a very general understanding of the role of the teacher, classroom dynamics, and school structure, at the end of the semester the PSTs displayed a critical awareness of their role in the classroom, how compliance with administration policies affects the classroom, and the lack of funding for schools and education. For example, in their essays they articulated that "teachers spend money from their pockets to buy supplies for children," "teachers don't get enough salary," "things are not always happy and sweet in teaching," "teaching as well as influence cannot be done by a single teacher's effort," and there is teaching value in "long-term moral influence rather than academic achievement." This critical awareness is necessary to manage realities that are out of a teacher's control, such as standardized testing in students 'non-dominant language(s). Although there was not enough time in the semester to discuss action plans, the PSTs did learn the value of having allies while navigating the school system which started from observing and reflecting.

3. Dialogic problem-posing pedagogy cultivated PSTs' sense of agency in negotiating problems that occurred with their placements, field experience, coursework requirements, CT' 'expectations, and TEs' implementation of pedagogy in philosophical opposition to the more familiar banking model.

Freire (2010) stated that the banking model of education places teachers on a pedestal as the ultimate classroom authority that controls how learners think and what they learn. As TEs, we moved away from the banking model to engage PSTs in envisioning new ways to solve old real-world problems. Dialogic problem-posing pedagogy facilitated this goal, as we believe PSTs are indeed researchers and problem solvers. In the power-sharing learning environment that we established, we led PSTs in a semester-long dialogue, including the RBP. There is no doubt that PSTs found this type of progressive pedagogy challenging, but more importantly, as they found their voices, they advocated for their needs and rights in 
this process. We believe that dialogic problem-posing pedagogy supported the PSTs in recognizing different types of oppression, acknowledging people's agency and value, and including learners in decisionmaking, evidenced by PSTs 'gradual movement away from the banking model toward problem posing and problem solving. We believe that, regardless of the expected and unexpected problems that arose, PSTs sensed the pain, and awakened as they began to understand that the dynamics of school are not innocent but reflect the power and politics of dominant ideologies. Starting from here, PSTs also began their journey of in-depth analysis of the current educational issues and started to prepare for making changes in their learning and future teaching career.

\section{Conclusion}

This study highlighted the transformation of first-year PSTs' critical consciousness through engagement in a dialogic problem-posing pedagogy through an RBP in the class called Introduction with Internship in Bilingual Education/ESL. We aimed to answer the question, "How does dialogical problemposing pedagogy transform first-year PSTs' understanding of what counts as good teaching in the current educational context?"

We engaged the PSTs in the process of conscientização, which deepened their understanding of how the relationship between children's socio-cultural and economic backgrounds and the school structure drives children's academic performance. In this study, PSTs were invited to shape and reshape themselves by challenging their own status quo and exploring a progressive pedagogy. We wanted to escape the banking model of education, which promotes blind obedience to socialized ways of thinking, being, and doing that move people away from managing their realities (Chomsky, 2002). In the banking model, instead of devising conditions in which learners co-construct knowledge, learners, including low-income, disadvantaged children, are submerged into a type of schooling that leads them to uncritically consume the information delivered to them. The information delivered and consumed ultimately serves the dominant class that presents this information as knowledge.

As a part of the process, we reflected on our challenges and limitations. First, one of our class sections took place in a classroom in which the desks were immovable. As a result, PSTs sat side-by-side in rows facing the board. We had requested a classroom in which we could gather in a circle and smaller groups, but that did not happen. In fact, we initially doubted that dialogue could take place in an environment with such an arrangement. This arrangement influenced the PSTs in that they had to turn their bodies every time someone spoke, and some of them, especially the ones sitting on the side, often became distracted and did not interact. Even though it was out of our hands, in this classroom we dealt with the contradiction of promoting a democratic type of pedagogy without having the tool of an appropriate physical arrangement. The other classroom, fortunately, had movable chairs, allowing us to arrange ourselves in a semi-circle or circle, which was more appropriate for promoting dialogue. In the first section, the banking model classroom setting thus jeopardized our dialogic process.

Second, multiple inquiries arose with regard to why the PSTs were not placed in private schools for their RBPs. The simple answer was because of our university's TEP partners with the public-school district. We as TEs defend public education because it is a constitutional right and available to all children regardless of their social, economic, ethnic, and citizenship status. We advocate for policies that promote ways in which public education can increase and equalize opportunities for children, ranging from informed curriculum decisions to ensuring teachers are well-paid and highly qualified. However, we could not dismiss PSTs' inquiries regarding the reasons they were not placed in private schools (even though they had completed a coursework module on the purpose of public schools). Thus, we assigned PSTs to groups to discuss their rationale(s) for having private schools included in the TEP. This demonstrated that in a dialogic 
problem-posing pedagogy, students have the agency to question the status quo of the curriculum, our partnerships, and choices made by administrators with regard to their education program.

Their inquiries encourage us to include in future coursework a discussion of narratives that either encourage or denounce the privatization of public schooling. We can ask critical questions (Janks, 2000; Janks \& Ivanic, 1992) to start a dialogue that challenges the roles of public and private schools, such as: What are the major differences between public and private schools? As public school is a constitutional right, what can we do to improve it? There may be other questions that address PST's epistemological curiosity (Freire, 1998, 2010). Once PSTs understand the different sides of the issue, they could discuss who benefits from each type of school, who is excluded, and they can debate what purposes these schools serve. At that point, they could make a collective, informed argument whether or not they would advocate for different school settings in their TEP program, and if so, how they could make that happen.

Even with its challenges and limitations, this study adds important new insights to the literature, especially with regard to the role of dialogic problem-posing pedagogy in building curriculum collaboratively and promoting more democratic practices for use by future teachers. Using collective inquiry and decisionmaking processes, the PSTs brought their inquiries and insights, along with their voices (which gradually grew), and these were valued and integrated into praxis. Importantly, dialogic pedagogy offered opportunities for PSTs to engage with real-world issues and to analyze and propose alternatives to cope with those issues. Moreover, the findings of this study are significant in showing that both TEs and PSTs need to tap different perspectives about the same real-world issues. That means uncovering unexamined blind spots through the investigation of beliefs, especially when those beliefs conflict with those of others or/and crash into reality. Our findings suggest that dialogic pedagogy builds a foundation that transforms PSTs through research-based practicums, and through that research, TEs can better facilitate PSTs' problem-solving processes. Our research concluded as we witnessed the realization of engaging preservice teachers in conscientização through a semester of dialogic problem-posing pedagogy through an RPB.

\section{References}

Barbosa, P.D.O. (2018). Prospective teachers dismantling anti-bilingual hegemonic discourses: Exploring a pedagogy of participatory possibilities for "political clarity" and "political agency". (Publication No. 10985660) [Doctoral dissertation, New Mexico State University]. ProQuest Dissertation Publishing.

Bartolomé, L. I. (1998). The misteaching of academic discourses: The politics of language in the classroom. Boulder, CO: Westview Press.

Bartolome, L. (2004). Critical pedagogy and teacher education: Radicalizing prospective teachers. Teacher Education Quarterly, 31(1), 97-122.

Bartolomé, L. I. (2008). Ideologies in education: Unmasking the trap of teacher neutrality. New York, NY: Peter Lang.

Chomsky, N (2002). Media control: The spectacular achievements of propaganda (2nd ed.). New York, NY: Seven Stories Press.

Crawford, J. (2004). Educating English learners: Language diversity in the classroom. Los Angeles, CA: Bilingual Educational Services.

Fals-Borda, O. (1985). Knowledge and people's power: Lessons with peasants in Nicaragua, Mexico and Colombia. New Delhi, India: Indian Social Institute. 
Fals-Borda, O., \& Rahman, M. A. (1991). Action and knowledge: Breaking the monopoly with participatory action research. New York, NY: Apex Press.

Foss, K.F. \& Waters, W. (2007). Destination dissertation: A traveler's guide to a done dissertation. Lanham, MD: Rowman \& Littlefield Publishers, Inc.

Freire, P. (1998). Pedagogy of freedom: Ethics, democracy, and civic courage. Lanham: Rowman \& Littlefield, Inc.

Freire, P. (2010). Pedagogy of the oppressed (30th ed.). New York, NY: Continuum.

Freire, P. (2013). Education for critical consciousness. London: Bloomsbury Academic.

Freire, P., \& Macedo, D. P. (1987). Literacy: Reading the word \& the world. South Hadley, MA: Bergin \& Garvey.

Giroux, H. (1987). Introduction: Literacy and the pedagogy of political empowerment. In P. Freire \& D. Macedo (Authors), Literacy: Reading the word \& the world (pp. 1-27). Westport, CT: Bergin \& Garvin.

Giroux, H. (1997). The pedagogy and the politics of hope: Theory, culture and schooling. Boulder, CO: Westview Press.

Giroux, H. A. (2014). Neoliberalism's war on higher education. Chicago, IL: Haymarket Books.

Giroux, H. A. (2015). Education and the crisis of public values: Challenging the assault on teachers, students, and public education. New York, NY: Peter Lang.

Halliday, M.A.K. (1999). The notion of "context" in language education. In Ghadessey, M. (Ed.), Text and Context in Functional Linguistics (pp. 1-24). Amsterdam, The Netherlands: John Benjamins Publishing Co.

hooks, b. (2010). Teaching critical thinking: Practical wisdom. Cambridge, MA: South End Press Classics.

Janks, H. (2000). Domination, access, diversity and design: A synthesis for critical literacy education. Educational Review, 52(2), 175-86.

Janks, H. and Ivanic, R. (1992). Critical language awareness and emancipatory discourse. In N. Fairclough (ed.), Critical language awareness (pp. 305-31). London: Longman.

Kincheloe, J. L. (2008). Critical pedagogy primer. New York, NY: Peter Lang.

King, J.E. (1991). Dysconscious racism: Ideology, identity, and the miseducation of teachers. Journal of Negro Education, 60, 133-157.

Lincoln, Y. S., \& Guba, E. G. (1985). Naturalistic inquiry. Newbury Park, CA: Sage Publications.

Macedo, D. P. (2006). Literacies of power: What Americans are not allowed to know. Boulder, CO: Westview Press.

Madison, D.S. (2020). Critical ethnography: Methods, ethics, and performance. Thousand Oaks, CA: SAGE Publications, Inc.

Matusov, E. \& Marjonovic-Shane, A. (2017). Promoting students 'ownership of their own education through critical dialogue and democratic self-governance. Dialogic Pedagogy: An International Online Journal, 5, E1-E19. https://doi.org/10.5195/dpj.2017.199

Nader, R. (2012). The seventeenth solutions: Bold ideas for our american future. New York, NY: HarperCollins Publishers Inc. 
Pacheco, R.A. (2016). Teaching with mindfulness: A research praxis study about radical democratic participation in a multicultural education classroom. (Publication No.10142139) [Doctoral dissertation, New Mexico State University]. ProQuest Dissertation Publishing.

Puiggrós, A. (2006) Paulo freire and the 'pedagogy of hope'. Online: http://www.wacc.org.uk/wacc/ publications/media_development/archive/1997 4/paulo_freire_and_the_pedagogy_of_hope [accessed 14 August 2006].

Ravitch, D. (2010). The dream and life of the great American school system: How testing and choice are undermining education. New York, NY: Basic Books.

Robinson, C., \& Taylor, C. (2007). Theorizing student voice: Values and perspectives. Improving Schools, 10(1), 5-17. https://doi.org/10.1177/1365480207073702

Saldaña, J. (2009). The coding manual for qualitative researchers. Thousand Oaks, CA: Sage Publications Ltd.

Sanchez-Vázquez, A. (1977). The philosophy of praxis. Atlantic Highlands, NJ: Humanities Press.

Shor, I. (1996). When students have power: Negotiating authority in a critical pedagogy. Chicago, IL: University of Chicago Press.

Souto-Manning, M. (2010). Freire, teaching, and learning: Culture circles across contexts. New York, NY: Peter Lang Publishing, Inc.

Valencia, R. R. (2010). Dismantling contemporary deficit thinking: Educational thought and practice. New York, NY: Routledge.

Villegas, A. M. (1988). School failure and cultural mismatch: Another view. The Urban Review, 20(4), 253265. https://doi.org/10.1007/BF01120137

Weiner, L. (2012). The future of our schools: Teachers unions and social justice. Chicago, IL: Haymarket Books.

\section{(cc) EY}

New articles in this journal are licensed under a Creative Commons Attribution 4.0 United States License.

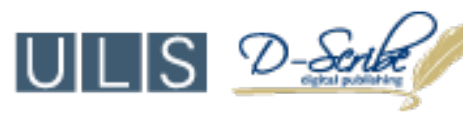

This journal is published by the University Library System, University of Pittsburgh as part of its D-Scribe Digital Publishing Program and is cosponsored by the University of Pittsburgh Press. 